\title{
Identification of differentially expressed genes and their subpathways in recurrent versus primary bone giant cell tumors
}

\author{
SHUXIN CHEN ${ }^{1,2,4^{*}}$, CHUNQUAN LI ${ }^{1,2,5^{*}}$, BINGLI WU ${ }^{1,2}$, CHUNLONG ZHANG $^{5}$, CHENG LIU $^{4}$, \\ XIAOXU LIN ${ }^{4}$, XIANGQIAO WU ${ }^{4}$, LINGLING SUN ${ }^{1,3}$, CHUNPENG LIU $^{1,3}$, BO CHEN $^{1,3}$, \\ ZHIGANG ZHONG ${ }^{4}$, LIYAN XU ${ }^{1,3}$ and ENMIN $\mathrm{LI}^{1,2}$
}

\author{
${ }^{1}$ Key Laboratory of Molecular Biology in High Cancer Incidence Coastal Chaoshan Area of Guangdong \\ Higher Education Institutes, ${ }^{2}$ Department of Biochemistry and Molecular Biology, ${ }^{3}$ Institute of Oncologic Pathology, \\ Medical College of Shantou University; ${ }^{4}$ Department of Orthopedic Surgery, Shantou Central Hospital, \\ Affiliated Shantou Hospital of Sun Yat-Sen University, Shantou $515041 ;{ }^{5}$ College of Bioinformatics \\ Science and Technology, Harbin Medical University, Harbin 150081, P.R. China
}

Received March 18, 2014; Accepted May 20, 2014

DOI: 10.3892/ijo.2014.2501

\begin{abstract}
Giant cell tumor (GCT) of the bone is a benign but locally aggressive bone neoplasm with a strong tendency to develop local recurrent and metastatic disease. Thus, it provides a useful model system for the identification of biological mechanisms involved in bone tumor progression and metastasis. This study profiled 24 cases of recurrent versus primary bone GCT tissues using QuantiGene 2.0 Multiplex Arrays that included Human p53 80-Plex Panels and Human Stem Cell 80-Plex Panels. A total of 32 differentially expressed genes were identified, including the 20 most upregulated genes and the 12 most downregulated genes in recurrent GCT. The genes identified are related to cell growth, adhesion, apoptosis, signal transduction and bone formation. Furthermore, iSubpathwayMiner analyses were performed to identify significant biological pathway regions (subpathway) associated with this disease. The pathway analysis identified 11 statistically significant enriched subpathways, including pathways in cancer, p53 signaling pathway, osteoclast differentiation pathway and Wnt signaling pathway. Among these subpathways, four
\end{abstract}

Correspondence to: Dr Zhigang Zhong, Department of Orthopedic Surgery, Shantou Central Hospital, Affiliated Shantou Hospital of Sun Yat-Sen University, 114 Waima Road, Shantou, Guangdong 515041, P.R. China

E-mail: stzzg@163.com

Professor Liyan Xu, Institute of Oncologic Pathology, Shantou University Medical College, 22 Xinling Road, Shantou, Guangdong 515041, P.R. China

E-mail: lyxu@stu.edu.cn

${ }^{*}$ Contributed equally

Key words: giant cell tumor, microarray analysis, KEGG pathway, subpathway, MDM2 genes (IGF1, MDM2, STAT1 and RAC1) were presumed to play an important role in bone GCT recurrence. The differentially expressed MDM2 protein was immunohistochemically confirmed in the recurrent versus primary bone GCT tissues. This study identified differentially expressed genes and their subpathways in recurrent GCT, which may serve as potential biomarkers for the prediction of GCT recurrence.

\section{Introduction}

Giant cell tumor of the bone is a relatively uncommon neoplasm, which is a benign but locally aggressive bone neoplasm characterized by massive bone destruction at the epiphysis of the long bone and has a strong tendency to develop local recurrence and metastasis (1). GCT accounts for 4-5\% of primary bone tumors and up to $20 \%$ of benign bone tumors (2). Statistically, $80 \%$ of GCTs have a benign clinical course with a local recurrent rate of $20-50 \%$. Approximately $10 \%$ will undergo malignant transformation and 1-4\% will have pulmonary metastases even in cases with a benign histology (3). In China, GCT incidence is significantly higher and observed in roughly $20 \%$ of all primary bone tumors (4). To date, surgery is the primary treatment for GCT with unresectable tumors being treated with radiotherapy (5), and these treatment regimens have remained unchanged for much of the past three decades, which is partially due to the lack of randomized clinical trials (4) and lack of chemotherapy options. Since the tissue origin of GCT remains to be determined, and its clinical behavior is unpredictable, the accurate prediction of its recurrence and metastasis is still not available using clinical diagnosis, radiology and histology (6). Thus, novel approaches are urgently required to better understand the molecular mechanisms of GCT carcinogenesis and to therefore provide meaningful strategies for the effective control of GCT in the clinic.

Currently, profiling of altered genes and pathways using gene chips is a useful method and an efficient alternative strategy to establish disease-pathway relationships $(7,8)$. 
Information on disease-related genes, such as from the Genetic Association Database (GAD) (9), is increasingly available for constructing high quality disease-metabolic pathway relationships. Different expression profiles of the p53 pathway and stem cell pathway genes was considered to be a major cause of the occurrence of GCT and promoters of malignant transformation and metastasis (10). However, little is known about the role that the p53 pathway plays underlying tumorigenesis and development of recurrent GCT. Moreover, there is strong evidence showing that the neoplastic cells of GCT are developed from mesenchymal stem cells (11). In recent years, more attention has been paid to subpathway (local area of the entire biological pathway), which can provide more detailed information of complex diseases in high-throughput data analysis, because critical genes may not be significantly enriched in the whole pathway, but nevertheless play key roles $(12,13)$. Therefore, in this study, we profiled differentially expressed genes in recurrent versus primary GCT tissues and identified significant subpathways to further explore the biological mechanisms involved in the recurrence of GCT. Thus, the aim of this study was to improve the understanding of these genes and pathways in the regulation of GCT invasion, recurrence and metastasis, and therefore to evaluate them as potential biomarkers for the early detection and prediction of tumor recurrence.

\section{Materials and methods}

Study population. A total of 24 cases of bone GCT, including 12 primary and 12 recurrent tumors, were obtained from 17 GCT patients who were surgically treated in the Department of Orthopedics Surgery, Shantou Hospital of Zhongshan University, between March 2001 and April 2010. All cases were diagnosed by the experienced subspecialty bone and soft-tissue pathologists, and confirmed by another study pathologist. The clinicopathological data of each patient were retrieved from their medical records and are summarized in Table I. The Institutional Review Board of Shantou Hospital of Zhongshan University approved the study protocol and each patient signed an informed consent form before recruitment into this study.

Whole genome cDNA QuantiGene 2.0 microarray analysis. Formalin-fixed and paraffin-embedded (FFPE) non-cancer and cancer tissues were isolated, separately by scraping, and placed into $1.5-\mathrm{ml}$ microcentrifuge tubes for processing of tissue homogenates according to the procedure as described in the QuantiGene sample processing kit for FFPE tissues (Affymetrix, Inc., Santa Clara, CA, USA). Briefly, $300 \mu 1$ of homogenizing tissue mixture, containing 10 deparaffinized $10-\mu \mathrm{m}$ sections, were supplemented with $3 \mu \mathrm{l}$ of proteinase $\mathrm{K}$ $(50 \mu \mathrm{g} / \mu \mathrm{l})$ and incubated overnight at $65^{\circ} \mathrm{C}$. The following day, the tissue homogenates were separated from debris by brief centrifugation and transferred to a new tube. The resulting tissue homogenates were frozen at $-80^{\circ} \mathrm{C}$ and stored until further use.

A QuantiGene 2.0 Multiplex assay system, containing Human p53 80-Plex Panels and Human Stem Cell 80-Plex Panels, was purchased from Affymetrix, Inc. The QuantiGene 80-Plex assay was performed according to the recommended protocol of QuantiGene 2.0 reagent systems (Affymetrix, Inc.). Briefly, $40 \mu \mathrm{l}$ of tissue homogenate was mixed with $33.3 \mu \mathrm{l}$ of lysis mixture, $1 \mu \mathrm{l}$ of blocking reagent, $0.3 \mu 1$ of 2.0 probe set, and $25.4 \mu \mathrm{l}$ of nuclease-free water. The reactions were placed in a 96-well capture plate covalently coated with capture probes and incubated for $16 \mathrm{~h}$ at $54^{\circ} \mathrm{C}$. Wells were washed three times with wash buffer to remove unbound material. For signal amplification, with $100 \mu 1$ of 2.0 Pre-Amplifier working reagent, $100 \mu 1$ of Amplifier working reagent was added to each sample and incubated for $1 \mathrm{~h}$ each at $50^{\circ} \mathrm{C}$, respectively. To detect the signal, to each sample was added $100 \mu \mathrm{l}$ of 2.0 substrate, the samples were sealed and incubated for $5 \mathrm{~min}$. Luminescence levels were then measured using a luminometer (Victor Light; Perkin-Elmer, Waltham, MA, USA). Duplicate assays were performed for all samples, and homogenizing buffer was used as background control. To verify that the resulting assay signals were linearly proportional to the sample input, a 2-fold dilution series of each sample was performed. The RNA level of PGK1, TBP, HPRT1, GUSB and TFRC (reference genes) were measured to normalize the data.

Function enrichment analysis. We used the iSubpathwayMiner package that was developed by our laboratory (12) to identify the pathways of the differentially expressed genes in recurrent vs. primary bone GCT tissues. The tool was an R package for flexible biological pathway identification from the KEGG database (14), which covered not only the entire pathway level but also the subpathway level. During enrichment analyses, we performed entire pathway and subpathway identification for the differentially expressed genes based on the hypergeometric test. The corresponding GCT data were integrated with p53 gene and stem cell data and then into the corresponding gene product nodes (referred to as signature nodes) within the pathway. The lenient distance similar to the signature nodes within the pathway structure were analyzed to locate key cascade subpathway regions. Finally, a hypergeometric test was used to evaluate the enrichment significance of these subpathway regions.

Immunohistochemistry. We also performed immunohistochemistry using the PV-9000 2-step plus Poly-HRP anti-mouse/rabbit IgG detection system (ZSGB-BIO) and the liquid DAB substrate kit (ZSGB-BIO) to assess expression of MDM2 in GCT tissues using an MDM2 antibody (cat no. ZA-0519; ZSGB-BIO, Beijing, China). Briefly, 24 cases of GCT tissues were built to form a tissue microarray (TMA) and prepared for $4 \mu \mathrm{m}$ sections. For immunohistochemistry, the TMA sections were subjected to dewaxing in xylene and rehydration in a series of graded alcohols, and then subjected to antigen retrieval with a pressure cooker for $10 \mathrm{~min}$ in $0.01 \mathrm{M}$ sodium citrate buffer ( $\mathrm{pH}$ 6.0). After that, the sections were submerged in a peroxidase quenching solution, containing one part of $30 \%$ hydrogen peroxide to nine parts of distilled water, for $10 \mathrm{~min}$ and then washed with phosphatebuffered saline (PBS) three times for 2 min each. The sections were incubated in a moist chamber with $0.1 \mathrm{ml}$ of blocking serum solution for $10 \mathrm{~min}$ and then further incubated with 0.1 $\mathrm{ml}$ primary antibody for $30 \mathrm{~min}$. After rinsing with PBS three times for $2 \mathrm{~min}$ each, $0.1 \mathrm{ml}$ of HRP polymer conjugate was added to each section and incubated for $10 \mathrm{~min}$, followed by a 
Table I. Clinical characteristics of recurrent and primary bone GCT patients.

\begin{tabular}{cllclll}
\hline Case & Primary/recurrent & Sex & Age (years) & \multicolumn{1}{c}{ Site } & Campanacci's grading & Surgical treatment \\
\hline 1 & Primary & Female & 25 & Femur & I & Curettage \\
& Recurrences & Female & 27 & Femur & III & Wide resection \\
2 & Primary & Male & 44 & Radius & I & Curettage \\
& Recurrences & Male & 46 & Radius & II & Curettage \\
& Recurrences & Male & 48 & Radius & III & Wide resection \\
3 & Primary & Male & 23 & Tibia & I & Curettage \\
& Recurrences & Male & 24 & Tibia & II & Curettage \\
4 & Primary & Female & 20 & Vertebra & I & Curettage \\
& Recurrences & Female & 21 & Vertebra & II & Curettage \\
5 & Primary & Female & 26 & Tibia & I & Curettage \\
& Recurrences & Female & 26 & Tibia & I & Curettage \\
& Recurrences & Female & 27 & Tibia & II & Curettage \\
6 & Primary & Male & 18 & Fibula & I & Wide resection \\
7 & Recurrences & Male & 40 & Humerus & III & Wide resection \\
8 & Recurrences & Male & 49 & Femur & III & Wide resection \\
9 & Recurrences & Male & 28 & Tibia & III & Curettage \\
10 & Recurrences & Male & 48 & Femur & III & Wide resection \\
11 & Primary & Female & 45 & Radius & II & Curettage \\
12 & Recurrences & Male & 28 & Femur & III & Wide resection \\
13 & Primary & Female & 19 & Femur & II & Curettage \\
14 & Primary & Male & 50 & Humerus & II & Curettage \\
15 & Primary & Female & 31 & Femur & II & Curettage \\
16 & Primary & Female & 20 & Metacarpus & I & Curettage \\
\hline & Primary & Male & 23 & Tibia & I & Curettage \\
\hline
\end{tabular}

rinse with PBS. Next, the sections were incubated with DAB chromogen solution for 3-10 min and subsequently counterstained with Mayer's hematoxylin, dehydrated and mounted. The negative controls were incubated with $10 \%$ normal goat serum to substitute the primary antibody. Immunostained TMA sections were then reviewed and scored in a blinded manner by at least two independent investigators. The positive signal was observed in tumor cell cytoplasm, and scored as the estimated percentage of staining. MDM2 immunoreactivity was classified into three categories as negative $(<20 \%$ tumor cells displaying cytoplasmic staining); heterogeneous (20-79\% tumor cells with cytoplasmic reactivity); and homogeneous (>80\% tumor cells with intense cytoplasmic staining).

Statistical analysis. All statistical analyses were performed by using SPSS 11.0 software (SPSS, Chicago, IL, USA). Statistical analyses between primary and recurrent groups were determined by using the Kruskal Wallis test. A P-value $<0.05$ was considered statistically significant.

\section{Results}

Identification of differentially expressed genes in recurrent $v s$. primary bone GCT. In this study, we analyzed differentially expressed genes in recurrent vs. primary bone GCT tissues using QuantiGene 2.0 Multiplex assay. We identified a total of 32 differentially expressed genes using fold-change (FD $>2$ or FD <0.5), including 20 most upregulated genes and 12 most downregulated genes in recurrent bone giant cell tumor tissues versus the primary tumors (Table II). These genes are related to cell growth, adhesion, apoptosis, signal transduction, and bone formation, indicating that they may play roles in bone GCT progression, such as recurrence or metastasis.

Functional analysis of the differentially expressed genes. We performed pathway enrichment analysis using the differentially expressed genes in recurrent GCT tissues and identified six gene pathways (Table III). We then used the gene pathway data to locate the important pathway regions, and tested the regions by entering the differentially expressed genes into the p53 and stem data set of 150 genes for the pathway enrichment. Thus, we found a total of 11 subpathways (Table IV). It needs to be pointed out that 6 of these subpathways were not identifiable by the entire pathway identification method. Only focal adhesion pathway is significant in both entire and subpathway identification methods. If we only adopted the entire pathway identification method, these pathways could be ignored due to their high 
Table II. Differentially expressed genes between the primary and recurrent bone giant cell tumor tissues.

\begin{tabular}{|c|c|c|}
\hline Name & Full name & Fold change \\
\hline NANOG & Nanog homeobox & 62.01 \\
\hline CD4 & CD4 molecule & 23.97 \\
\hline TIMP3 & Tissue inhibitor of metalloproteinases 3 & 13.31 \\
\hline ADAR & Adenosine deaminase, RNA-specific & 10.63 \\
\hline MDM2 & Murine double minute 2 & 6.17 \\
\hline NUMB & Numb homolog (Drosophila) & 4.98 \\
\hline STAT1 & Signal transducer and activator of transcription 1 & 4.89 \\
\hline BAX & BCL2-associated X protein & 4.16 \\
\hline PAFAH1B1 & Platelet-activating factor acetylhydrolase $1 \mathrm{~b}$, regulatory subunit 1 (45 kDa) & 3.96 \\
\hline RAC1 & Ras-related C3 botulinum toxin substrate 1 & 3.62 \\
\hline $\mathrm{CDH} 2$ & Cadherin 2 , type $1, \mathrm{~N}$-cadherin (neuronal) & 3.47 \\
\hline NFKB1 & Nuclear factor of $\kappa$ light polypeptide gene enhancer in B-cells 1 & 3.32 \\
\hline NCSTN & Nicastrin & 3.00 \\
\hline CD8A & CD8a molecule & 2.27 \\
\hline PGK1 & Phosphoglycerate kinase 1 & 1.71 \\
\hline IGF1 & Insulin-like growth factor 1 (somatomedin C) & 1.47 \\
\hline BTG2 & BTG family, member 2 & 1.34 \\
\hline MME & Membrane metallo-endopeptidase & 1.17 \\
\hline CXCL12 & Chemokine (C-X-C motif) ligand 12 & 1.10 \\
\hline JUN & Jun proto-oncogene & 0.21 \\
\hline FZD1 & Frizzled family receptor 1 & -1.81 \\
\hline HK2 & Hexokinase 2 & -1.86 \\
\hline TFRC & Transferrin receptor (p90, CD71) & -2.22 \\
\hline E2F1 & E2F transcription factor 1 & -3.38 \\
\hline MYC & v-myc myelocytomatosis viral oncogene homolog (avian) & -7.67 \\
\hline DVL3 & Dishevelled, dsh homolog 3 (Drosophila) & -8.62 \\
\hline BMP1 & Bone morphogenetic protein 1 & -10.28 \\
\hline EGR1 & Early growth response 1 & -14.41 \\
\hline FGFR1 & Fibroblast growth factor receptor 1 & -20.25 \\
\hline BMP2 & Bone morphogenetic protein 2 & -36.26 \\
\hline COL1A1 & Collagen, type I, $\alpha 1$ & -469.8 \\
\hline SERPINE1 & Serpin peptidase inhibitor, clade $\mathrm{E}$ (nexin, plasminogen activator inhibitor type 1 ), member 1 & -37.99 \\
\hline
\end{tabular}

Table III. The newly identified gene pathways after the pathway enrichment analysis of the differentially expressed genes.

\begin{tabular}{|c|c|c|c|c|}
\hline Pathway ID & Pathway name & P-value & Ann molecule list & AnnBg molecule list \\
\hline path:04640 & $\begin{array}{l}\text { Hematopoietic } \\
\text { cell lineage }\end{array}$ & 0.007708 & CD8A; TFRC; MME; CD4 & CD8A; TFRC; MME; CD44; IL6; TNF; CD4 \\
\hline path:04145 & Phagosome & 0.018792 & TFRC; RAC1 & TFRC; RAC1 \\
\hline path:04974 & $\begin{array}{l}\text { Protein digestion } \\
\text { and absorption }\end{array}$ & 0.018792 & MME; COL1A1 & MME; COL1A1 \\
\hline path:05340 & $\begin{array}{l}\text { Primary } \\
\text { immunodeficiency }\end{array}$ & 0.018792 & $\mathrm{CD} 8 \mathrm{~A} ; \mathrm{CD} 4$ & CD8A; CD4 \\
\hline path:04514 & $\begin{array}{l}\text { Cell adhesion } \\
\text { molecules (CAMs) }\end{array}$ & 0.036157 & $\mathrm{CD} 8 \mathrm{~A} ; \mathrm{CDH} 2 ; \mathrm{CD} 4$ & CD8A; VCAN; NCAM1; CDH2; CDH1; CD4 \\
\hline path:04510 & Focal adhesion & 0.049058 & IGF1; COL1A1; JUN; RAC1 & $\begin{array}{l}\text { MAPK8; RHOA; IGF1; CCND1; COL1A1; } \\
\text { PTEN; JUN; BCL2; PRKCA; IGF1R; RAC1 }\end{array}$ \\
\hline
\end{tabular}


Table IV. The statistically significant subpathways identified by iSubpathwayMiner.

\begin{tabular}{|c|c|c|c|c|}
\hline $\begin{array}{l}\text { Subpathway } \\
\text { ID }\end{array}$ & $\begin{array}{l}\text { Pathway } \\
\text { name }\end{array}$ & P-value & $\begin{array}{l}\text { Differential genes } \\
\text { within the subpathway }\end{array}$ & $\begin{array}{l}\text { Genes within the } \\
\text { subpathway }\end{array}$ \\
\hline path:05200_1 & $\begin{array}{l}\text { Pathways in } \\
\text { cancer }\end{array}$ & 0.002258 & $\begin{array}{l}\text { DVL3; FZD1; IGF1; STAT1; } \\
\text { FGFR1; NFKB1; MDM2; } \\
\text { MYC; RAC1 }\end{array}$ & $\begin{array}{l}\text { DVL3; DVL1; FZD1; RHOA; FZD8; } \\
\text { FZD3; IGF1; STAT1; TCF7; FGFR1; } \\
\text { NFKB1; MDM2; MYC; KRAS; } \\
\text { RELA; IGF1R; RAC1 }\end{array}$ \\
\hline path:04062_1 & $\begin{array}{l}\text { Chemokine } \\
\text { signaling } \\
\text { pathway }\end{array}$ & 0.007513 & STAT1; NFKB1; CXCL12; RAC1 & STAT1; NFKB1; CXCL12; RELA; RAC1 \\
\hline path:04115_1 & $\begin{array}{l}\text { p53 signaling } \\
\text { pathway }\end{array}$ & 0.007513 & IGF1; SERPINE1; MDM2; BAX & IGF1; TP53; SERPINE1; MDM2; BAX \\
\hline path:04380_1 & $\begin{array}{l}\text { Osteoclast } \\
\text { differentiation }\end{array}$ & 0.007513 & STAT1; NFKB1; JUN; RAC1 & STAT1; NFKB1; JUN; RELA; RAC1 \\
\hline path:04010_1 & $\begin{array}{l}\text { MAPK } \\
\text { signaling } \\
\text { pathway }\end{array}$ & 0.019088 & NFKB1; MYC; JUN; RAC1 & $\begin{array}{l}\text { MAPK8; NFKB1; MYC; JUN; } \\
\text { RELA; RAC1 }\end{array}$ \\
\hline path:04510_1 & Focal adhesion & 0.019088 & IGF1; COL1A1; JUN; RAC1 & $\begin{array}{l}\text { MAPK8; IGF1; COL1A1; JUN; } \\
\text { IGF1R; RAC1 }\end{array}$ \\
\hline path:05215_1 & Prostate cancer & 0.019088 & IGF1; FGFR1; NFKB1; MDM2 & $\begin{array}{l}\text { IGF1; FGFR1; NFKB1; MDM2; RELA; } \\
\text { IGF1R }\end{array}$ \\
\hline path:05220_1 & $\begin{array}{l}\text { Chronic } \\
\text { myeloid } \\
\text { leukemia }\end{array}$ & 0.030663 & NFKB1; MDM2; MYC & NFKB1; MDM2; MYC; RELA \\
\hline path:04310_2 & $\begin{array}{l}\text { Wnt signaling } \\
\text { pathway }\end{array}$ & 0.036904 & DVL3; FZD1; MYC; JUN; RAC1 & $\begin{array}{l}\text { DVL3; DVL1; FZD1; FZD8; FZD3; } \\
\text { TCF7; AXIN1; MYC; JUN; RAC1 }\end{array}$ \\
\hline path:04722_1 & $\begin{array}{l}\text { Neurotrophin } \\
\text { signaling } \\
\text { pathway }\end{array}$ & 0.037737 & NFKB1; JUN; BAX; RAC1 & $\begin{array}{l}\text { MAPK8; TP53; NFKB1; JUN; BAX; } \\
\text { RELA; RAC1 }\end{array}$ \\
\hline path:00010_1 & $\begin{array}{l}\text { Glycolysis/ } \\
\text { gluconeogenesis }\end{array}$ & 0.044385 & HK2; PGK1 & HK2; PGK1 \\
\hline
\end{tabular}

P-values threshold. However, these pathways were found statistically significant using the subpathway identification method. The result indicated that these subpathways may be associated with GCT recurrence.

The most significant subpathway was the 'pathways in cancer'. GCT, as tumor disease was obviously associated with the dysregulation of the pathway. We found that the differential gene IGF1, a growth factor, was located in the starting regions in the pathway (Fig. 1).

The third subpathway (path:04115_1) in Table I belonged to the p53 signaling pathway. The pathway was reported to be highly associated with giant cell tumor of bone (GCTB) (15-17). Gene p53 was located in the center of the pathway and identified within the subpathway path:04115_1 (Fig. 2). Moreover, MDM2 was localized in the central region of this subpathway.
The fourth subpathway path:04380_1, which belonged to the osteoclast differentiation pathway, was identified as significant in iSubpathwayMiner, which yielded a P-value of 0.0075 . This pathway was associated with the localized bone destruction of GCTB (18). Mononuclear stromal cells in GCTs of bone have shown characteristics of the osteoblast lineage by expressing many osteoblast-associated differentiation markers (19). The bone resorption activity of osteoclasts can cause destructive osteolysis and consequent morbidity in GCT (18). The subpathway path:04380_1 contained four differential genes: JUN, NFKB1, STAT1 and RAC1 (Fig. 3).

The ninth subpathway (path:04310_2) belonged to the Wnt signaling pathway. The subpathway path:04310_2 contained MYC, JUN, and RAC1, most of which were localized in the endpoint of this pathway (Fig. 4). 


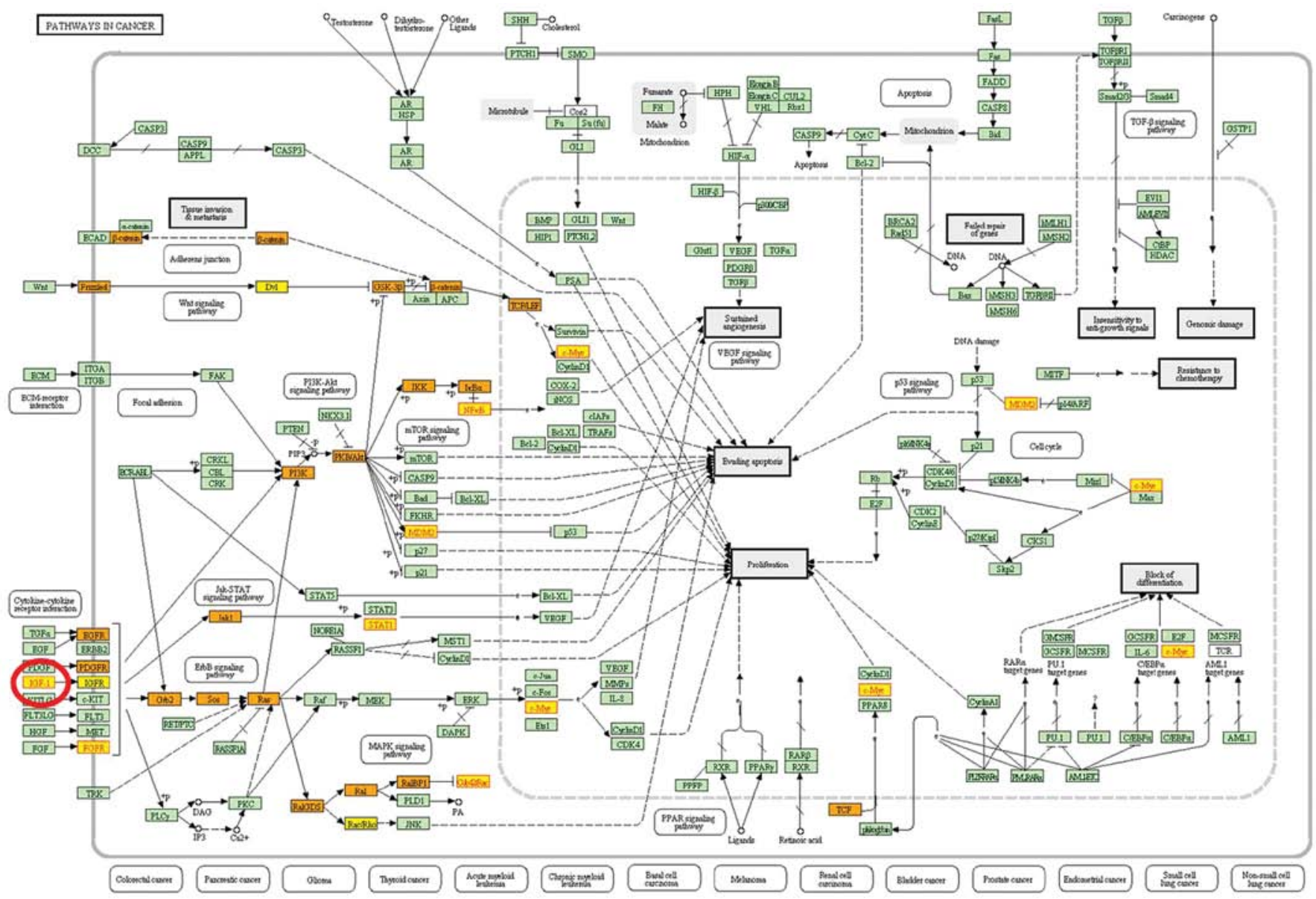

Figure 1. The differentially expressed genes in recurrent vs. primary bone GCT tissues belongs to the 'pathways in cancer'. The dark shade nodes indicate the key subpathway region (path:05200_1) identified by iSubpathwayMiner. The proteins mapped by differential genes are shown with red node labels and borders.

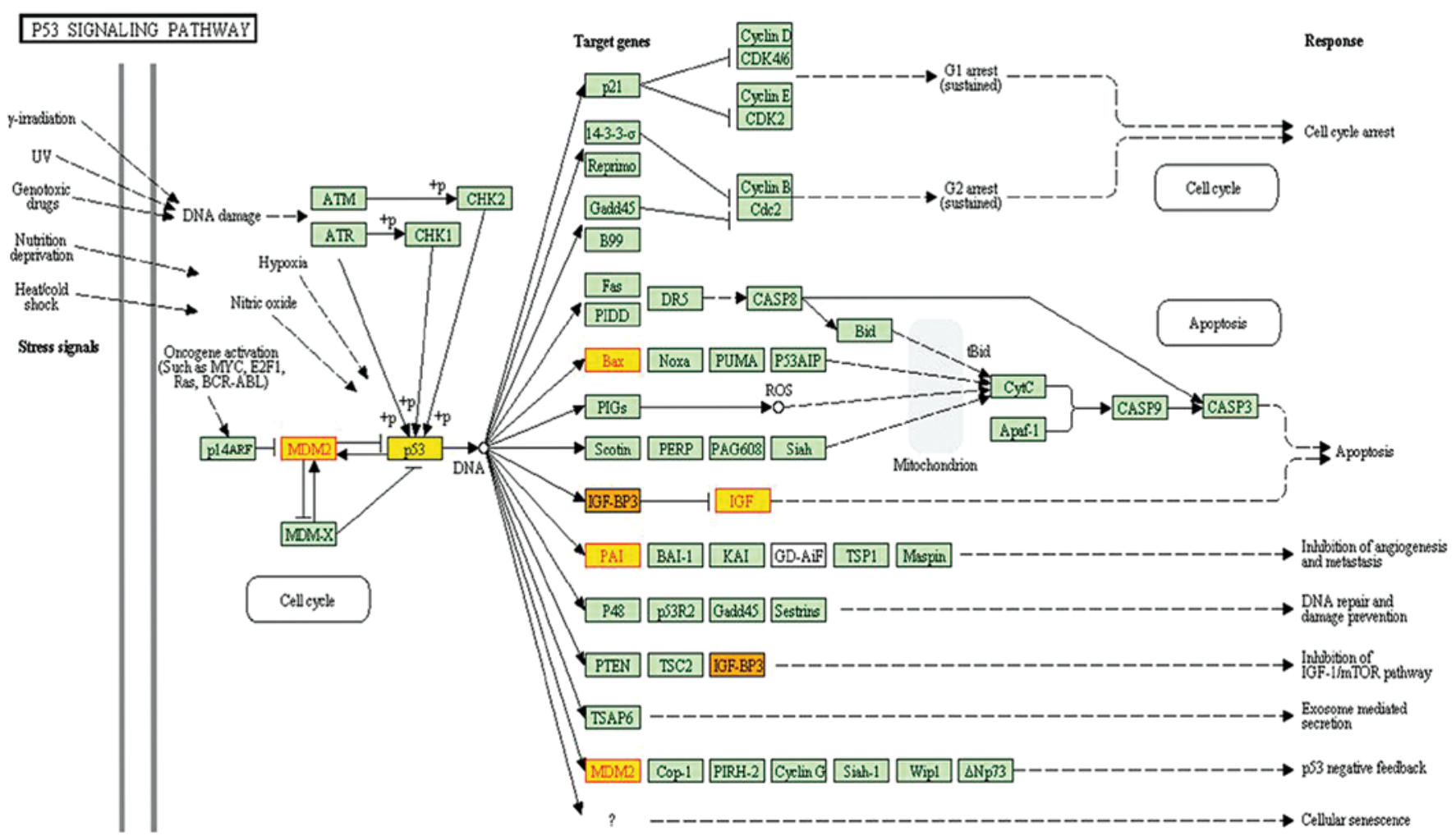

Figure 2. The $p 53$-signaling pathway was annotated from the differentially expressed genes. The dark shade nodes indicate the key subpathway region (path:04115_1) identified by iSubpathwayMiner. The proteins mapped by differential genes are shown with red node labels and borders. 


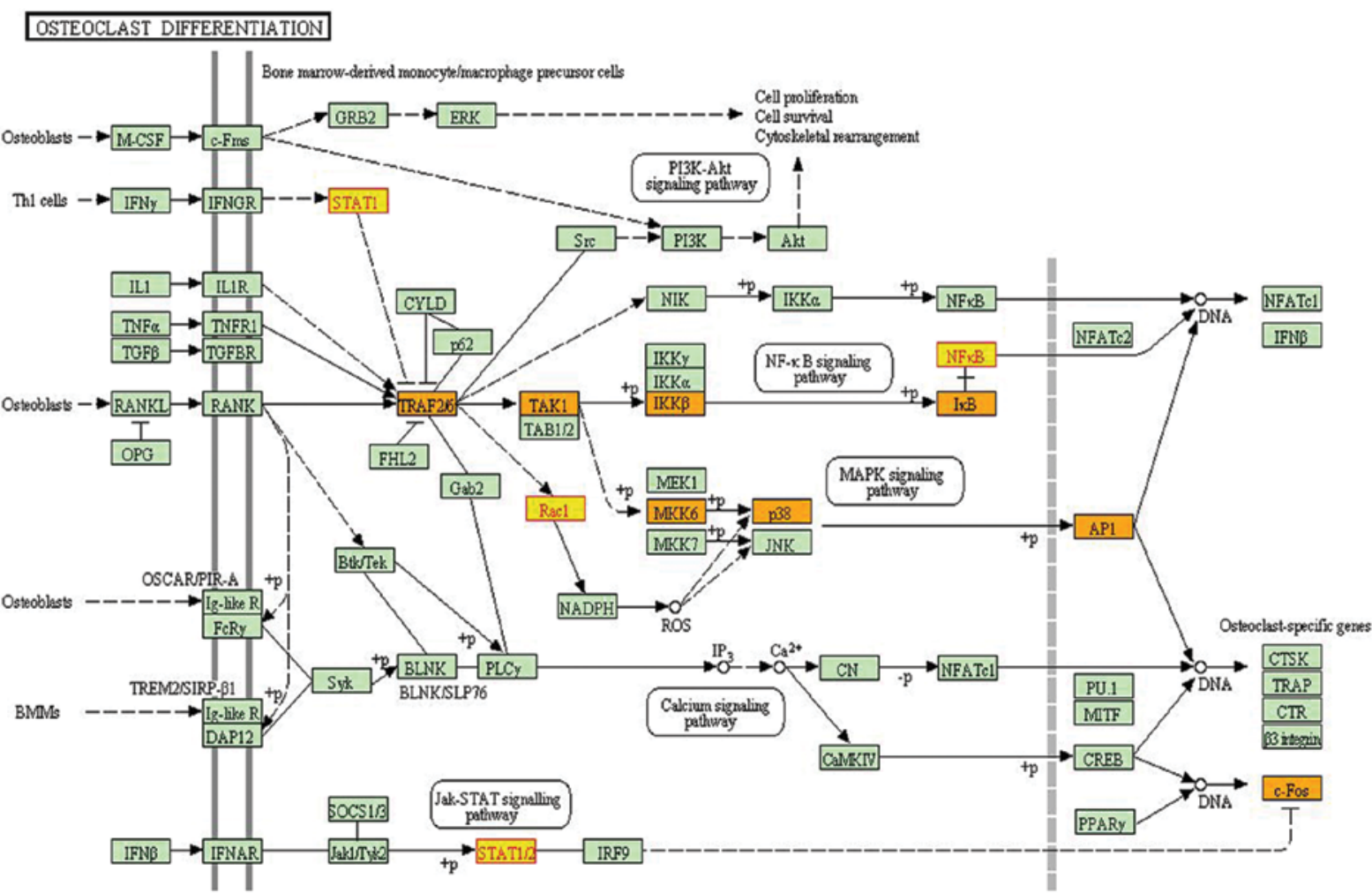

Figure 3. The osteoclast differentiation pathway was annotated from the differentially expressed genes. The dark shade nodes indicate the key subpathway region (path:04380_1) identified by iSubpathwayMiner. The proteins mapped by differential genes are shown with red node labels and borders.

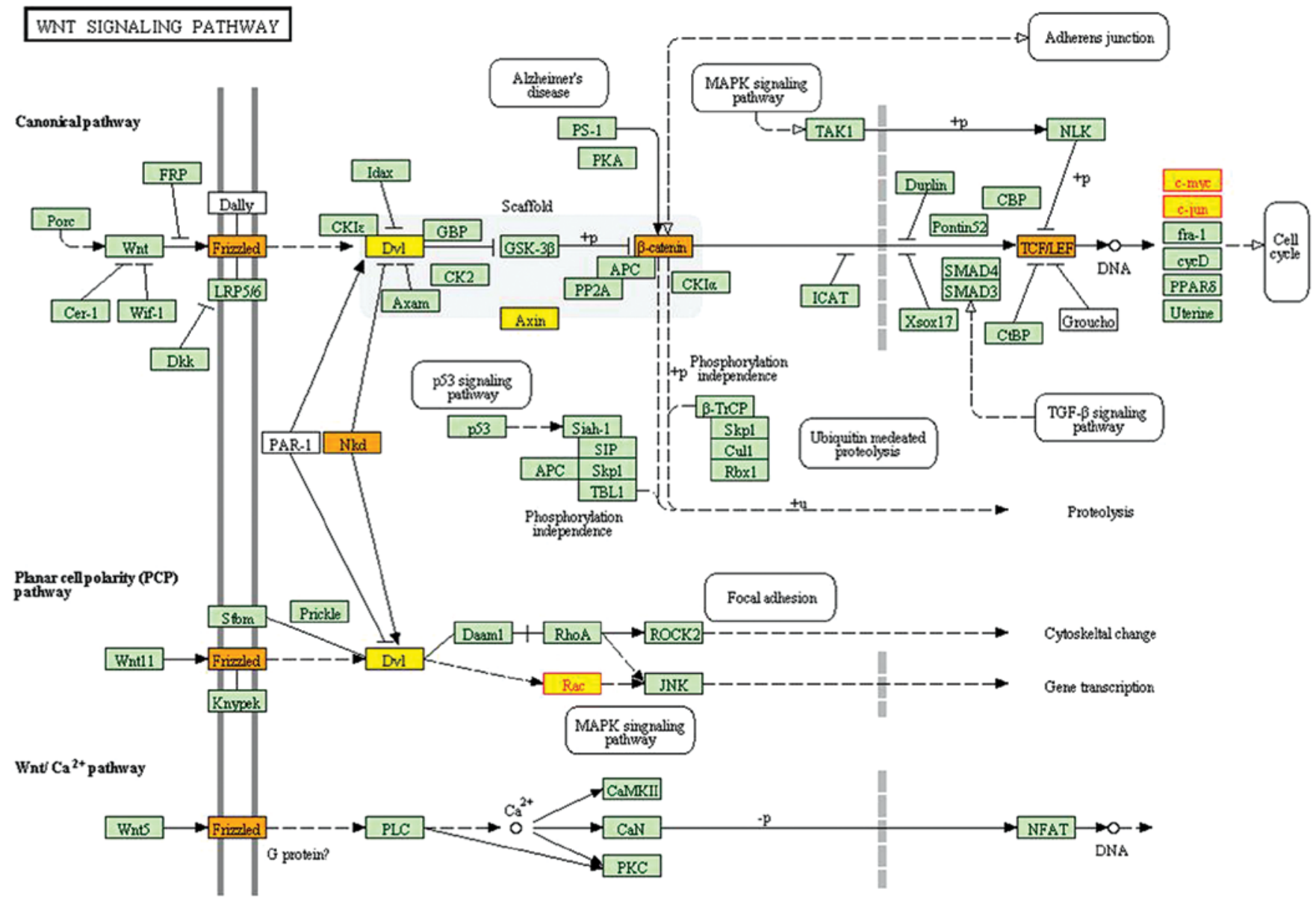

Figure 4. The Wnt signaling pathway was annotated from the differentially expressed genes. The dark shade nodes indicate the key subpathway region (path:04310_2) identified by iSubpathwayMiner. The proteins mapped by differential genes are shown with red node labels and borders. 

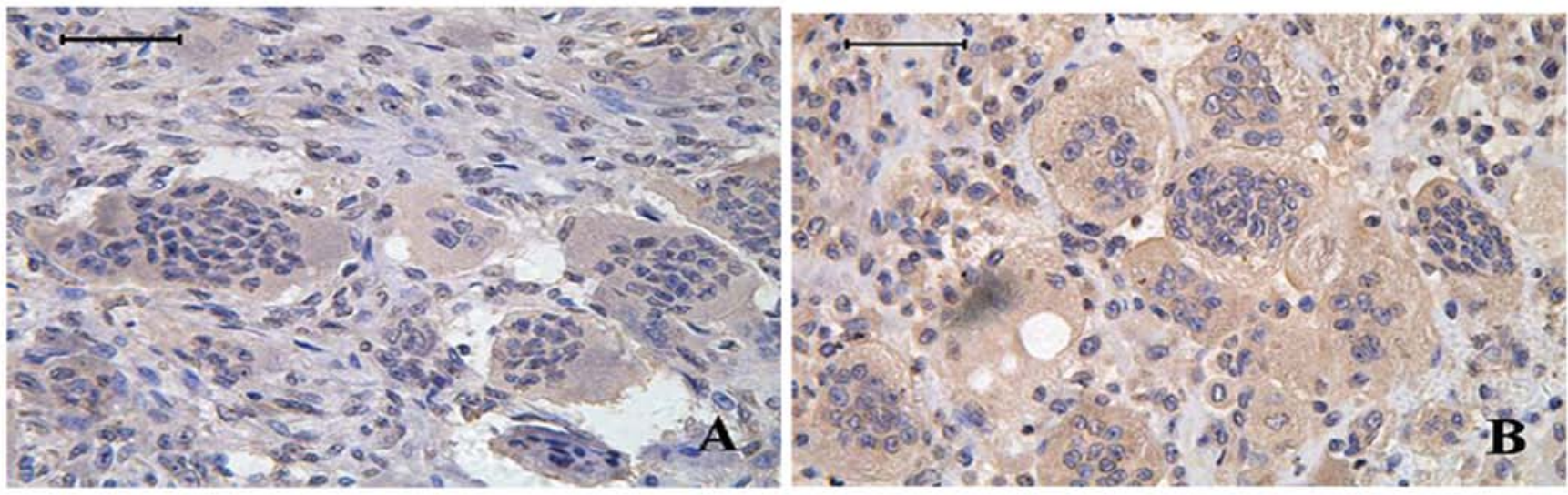

Figure 5. Immunohistochemical analysis of MDM2 expression in primary (A) and recurrent (B) bone GCT tissues. Bar, $50 \mu \mathrm{m}$.

Immunohistochemical validation of MDM2 expression in bone GCT tissues. After the above pathway analysis, we identified many risk genes in recurrent GCT. Among these risk genes, we chose MDM2 for immunohistochemical analysis in bone GCT tissues. MDM2 protein was observed in both multinucleated giant cells and mononuclear stromal cells in GCT tissues (Fig. 5). Comparing immunohistochemical results between the primary and recurrent bone GCT tissues, MDM2 was statistically significantly higher in recurrent tumors than primary tumors $\left(\mathrm{P}=0.015, \chi^{2}=5.86\right)$. MDM 2 is involved in the occurrence and development of GCT.

\section{Discussion}

Bone GCT is a benign but locally aggressive bone neoplasm with a strong tendency to develop a local recurrent and metastatic disease. Recently, two studies attempted to identify differentially expressed genes associated with GCT development and progression $(20,21)$. Altered expression of Ephrin A receptor, Claudin 7, CD52, FGFR3, and AMFR was found by Guenther et al (20), whereas Skubitz et al (21) reported that genes found to be overexpressed in GCTs included tartrateresistant acid phosphatase, the lysosomal $\mathrm{H}^{+}$-transporting ATPase, and osteoprotegrin ligand (OPGL). In our present study, we identified 32 differentially expressed genes in the primary vs. recurrent bone GCT tissues and we then used iSubpathwayMiner to annotate them into gene subpathways resulting 11 statistically significantly enriched subpathways. This study is just the first step to identify genes that are associated with bone GCT recurrence and further study is warranted to investigate them mechanistically in bone GCT to provide biomarkers or therapeutic targets.

The present study identified several critical genes and gene pathways that are associated with bone GCT recurrence. The first gene was IGF1, which regulates cell proliferation, differentiation and survival (22). IGFI plays an important role in normal bone growth, bone cell turnover and metabolism, and is a key factor in osteoblast proliferation and bone formation (23). IGF1 may be a possible prognostic marker useful in the identification of GCT patients at a higher risk of relapse with potential for development into a therapeutic agent against GCT. Moreover, the third subpathway (path:04115_1) belonged to the p53 signaling pathway and p53 is local- ized in the center of this pathway and identified within the subpathway path:04115_1. MDM2 was localized in the central region of this subpathway. Indeed, p53 is frequently mutated in GCT and could be useful in predicting tumor progression and local recurrence (15). p53 mutations were detected in the cases of secondary malignant giant-cell tumor without irradiation therapy (10). Masui et al showed that p53 expression levels correlated with the rates of lung metastasis and recurrence of GCT (16). These results suggest that p53 mutations may play an important role in malignant transformation of conventional GCT (17). MDM2 is a negative regulator of p53 and plays an important role in the p53-signaling pathway, suggesting a potentially high association with bone GCT development. Indeed, MDM2 has been found widely expressed in GCT (24). Thus, we further evaluated MDM2 expression in bone GCT tissues and the immune-reactivity of anti-MDM2 antibody was observed in osteoclast-like giant cells and mononuclear stromal cells. Statistical analyses showed that MDM2 expression was significantly higher in recurrent tumors than in primary tumors, suggesting that MDM2 might be associated with bone GCT recurrence.

Furthermore, the fourth subpathway path:04380_1 was the osteoclast differentiation pathway. This subpathway path:04380_1 contained four differentially expressed genes, including JUN, NFKB1, STAT1 and RACl. c-Jun is a component of the heterodimeric AP-1 transcription factor and was highly expressed in GCT stromal cells (25). JUN may also be involved in upregulation of matrix-metalloproteinases in GCT. MMP-2, MMP-13, and MMP-9 have been shown to be highly expressed in GCT tissues (26-28). Both MMP-2 and MMP-9 display several AP-1 consensus sequences within their promoter regions and may be directly upregulated by JUN (29). MMP-13 is responsible for optimizing the bone resorption capability of the giant cells, which is likely to be due to recruiting them to the bone surface $(27,30)$. JUN could influence normal ECM physiology, thereby promoting growth and destructiveness of GCT (27). NF- $\kappa \mathrm{B}$ has been shown to play an important role in many types of cancer and may also regulate tumor angiogenesis and invasiveness. NF- $\kappa \mathrm{B}$ provides a mechanistic link between inflammation and cancer and is a major transcriptional factor controlling the ability of both pre-neoplastic and malignant cells to resist apoptosisbased tumor-surveillance mechanisms (30). RANKL, as a 
negative regulator of $\mathrm{NF}-\kappa \mathrm{B}$, was identified as essential for osteoclast physiology $(31,32)$. RANKL is highly expressed in stromal cells of GCT $(33,34)$. As a potential therapeutic target of bone disease, Amgen developed a monoclonal antibody to RANKL (denosumab). Denosumab was studied in a recent proof-of-principle phase II study of 35 patients with recurrent or unresectable GCT (35). Twenty-six of the 31 patients with data reported reduced pain or improvement in the functional status. Radiologic evidence of bone repair was reported in nine patients. The treatment was generally well tolerated without treatment-related serious adverse events. Thus, blockade of RANKL signaling in patients with advanced or unresectable GCT could provide objective changes in tumor composition, reduced bony destruction, and clinical benefit. Signal transducer and activator of transcription 1 (STAT1), localized in the starting region of the subpathway path:04380_1 (Fig. 3), was reported to be associated with human breast cancer, melanoma, leukemia, lymphoma, and other cancers $(36,37)$. STAT1 has a critical role in regulation of bone growth and bone formation (38).

In addition, the ninth subpathway (path:04310_2) belongs to the Wnt signaling pathway. Several studies have shown that this pathway plays an important role in regulation of skeletal function, and the activation of Wnt signaling may induce osteoblast differentiation and osteoclastogenesis during the bone resorption process (39-41). Bone GCT was found associated with activation of the Wnt signaling pathway (42). This subpathway contained MYC, JUN, and RAC1, most of which were localized at the endpoint of this pathway. Gamberi et al (43) showed a strong correlation between c-Myc overexpression and GCT occurrence and its metastases. c-Myc protein was overexpressed in both giant cells and mononuclear cells, suggesting that both cell types are involved in progression of this tumor type (43). Previous studies found that Rac1 regulated a diverse array of cellular events, including formation of lamellipodia and membrane ruffles, cell cycle, cell adhesion and mobility (44-46). Rac1 is thought to play a significant role in the development of various cancers, including melanoma (45) and non-small cell lung cancer (46). As a result, it is now considered as a therapeutic target for these diseases (30). Rac1 can regulate survival signaling of osteoclasts and their bone resorption activity (47). A transgenic mouse model was used to confirm that Rac1 was the primary Rac isoform in regulating ROS production and the cytoskeleton organization during the multiple stages of osteoclast differentiation (48).

In conclusion, in the present study, we identified 32 genes that were differentially expressed in recurrent vs. primary bone GCT tissues and found them in multiple subpathways. Among them, four genes (IGF1, MDM2, STAT1 and RAC1) were located in key positions in these pathways. Further studies will confirm our current data and investigate their roles and functions in bone GCT progression.

\section{References}

1. Gupta R, Seethalakshmi V, Jambhekar NA, et al: Clinicopathologic profile of 470 giant cell tumors of bone from a cancer hospital in western India. Ann Diagn Pathol 12: 239-248, 2008.

2. Gamberi G, Serra M, Ragazzini P, et al: Identification of markers of possible prognostic value in 57 giant cell tumors of bone. Oncol Rep 10: 351-356, 2003.
3. Szendröi M: Giant cell tumor of bone. J Bone Joint Surg Br 86: 5-12, 2004

4. Thomas DM and Skubitz KM: Giant cell tumour of bone. Curr Opin Oncol 21: 338-344, 2009.

5. Mendenhall WM, Zlotecki RA, Scarborough MT, Gibbs CP and Mendenhall NP: Giant cell tumour of bone. Am J Clin Oncol 29: 96-99, 2006.

6. Eckardt JJ and Grogan TJ: Giant cell tumor of bone. Clin Orthop Relat Res 204: 45-58, 1986.

7. Khatri P, Sellamuthu S, Malhotra P, et al: Recent additions and improvements to the Onto-Tools. Nucleic Acids Res 33: W762-W765, 2005.

8. Wang K, Li M and Hakonarson $\mathrm{H}$ : Analysing biological pathways in genomewide association studies. Nat Rev Genet 11: 843-854, 2010.

9. Becker KG, Barnes KC, Bright TJ and Wang SA: The genetic association database. Nat Genet 36: 431-432, 2004.

10. Papanastassiou I, Ioannou M, Papagelopoulos PJ, et al: P53 expression as a prognostic marker in giant cell tumor of bone: a pilot study. Orthopedics 33: 307, 2010.

11. Wülling M, Delling G and Kaiser E: The origin of the neoplastic stromal cell in giant cell tumor of bone. Hum Pathol 34: 983-993, 2003

12. Li C, Li X, Miao Y, et al: SubpathwayMiner: a software package for flexible identification of pathways. Nucleic Acids Res 37: e131, 2009.

13. Li X, Li C, Shang D, et al: The implications of relationships between human diseases and metabolic subpathways. PLoS One 6: e21131, 2011.

14. Kanehisa M, Goto S, Sato Y, Furumichi M and Tanabe M: KEGG for integration and interpretation of large-scale molecular data sets. Nucleic Acids Res 40 (Database issue): D109-D114, 2012.

15. Oda Y, Sakamoto A, Saito T, et al: Secondary malignant giantcell tumor of bone: molecular abnormalities of p53 and H-ras gene correlated with malignant transformation. Histopathology 39: 629,2001

16. Masui F, Ushigome S and Fujii K: Giant cell tumor of bone: a clinicopathologic study of prognostic factors. Pathol Int 48: 723, 1998.

17. Gong L, Liu W, Sun X, et al: Histological and clinical characteristics of malignant giant cell tumor of bone. Virchows Arch 460: 327-334, 2012 .

18. Boyle WJ, Simonet SW and Lacey DL: Osteoclast differentiation and activation. Nature 423: 337-342, 2003.

19. Murata A, Fujita T, Kawahara N, Tsuchiya H and Tomita K: Osteoblast lineage properties in giant cell tumors of bone. J Orthop Sci 10: 581-588, 2005.

20. Guenther R, Krenn V, Morawietz L, et al: Giant cell tumors of bone: molecular profiling and expression analysis of Ephrin A receptor, Claudin 7, CD52, FGFR3 and AMFR. Pathol Res Pract 201: 649-663, 2005.

21. Skubitz KM, Cheng EY, Clohisy DR, Thompson RC and Skubitz AP: Gene expression in giant cell tumors. J Lab Clin Med 144: 193-200, 2004.

22. Kappel CC, Velez-Yanguas MC, Hirschfeld S and Helman LJ: Human osteosarcoma cell lines are dependent on insulin-like growth factor I for in vitro growth. Cancer Res 54: 2803-2807, 1994.

23. Bonjour JP, Schurch MA, Chevalley T, Ammann P and Rizolli R: Protein intake. IGF-1 and osteoporosis. Osteoporosis Int 7: 36-42, 1997.

24. de Souza PE, Paim JF, Carvalhais JN and Gomez RS: Immunohistochemical expression of p53, MDM2, Ki-67 and PCNA in central giant cell granuloma and giant cell tumor. J Oral Pathol Med 28: 54-58, 1999.

25. Mak IW, Turcotte RE, Popovic S, Singh G and Ghert M: AP-1 as a regulator of MMP-13 in the stromal cell of giant cell tumor of bone. Biochem Res Int 2011: 164197, 2011.

26. Rao VH, Singh RK, Delimont DC, et al: Interleukin-1beta upregulates MMP-9 expression in stromal cells of human giant cell tumor of bone. J Interferon Cytokine Res 19: 1207-1217, 1999.

27. Teti A, Farina AR, Villanova I, et al: Activation of MMP-2 by human GCT23 giant cell tumor cells induced by osteopontin, bone sialoprotein and GRGDSP peptides is RGD and cell shape change dependent. Int J Cancer 77: 82-93, 1998.

28. Mak IW, Seidlitz EP, Cowan RW, et al: Evidence for the role of matrix metalloproteinase-13 in bone resorption by giant cell tumor of bone. Hum Pathol 41: 1320-1329, 2010. 
29. Yoon SO, Park SJ, Yun CH and Chung AS: Roles of matrix metalloproteinases in tumor metastasis and angiogenesis. J Biochem Mol Biol 36: 128-137, 2003.

30. Karin M: Nuclear factor-kappaB in cancer development and progression. Nature 441: 431-436, 2006.

31. Dougall WC, Glaccum M, Charrier K, et al: RANK is essential for osteoclast and lymph node development. Genes Dev 13: 2412-2424, 1999.

32. Simonet WS, Lacey DL, Dunstan CR, et al: Osteoprotegerin: a novel secreted protein involved in the regulation of bone density. Cell 89: 309-319, 1997.

33. Morgan T, Atkins GJ, Trivett MK, et al: Molecular profiling of giant cell tumor of bone and the osteoclastic localization of ligand for receptor activator of nuclear factor kappaB. Am J Pathol 167: 117-128, 2005.

34. Geldyyev A, Koleganova N, Piecha G, et al: High expression level of bone degrading proteins as a possible inducer of osteolytic features in pigmented villonodular synovitis. Cancer Lett 255 : 275-283, 2007.

35. Thomas D, Henshaw R, Skubitz K, et al: Denosumab in patients with giant-cell tumor of bone: an open-label, phase 2 study. Lancet Oncol 11: 275-280, 2010.

36. Bowman T, Garcia R, Turkson J and Jove R: STATs in oncogenesis. Oncogene 19: 2474-2488, 2000.

37. Boudný V, Kocák I, Lauerová L and Kovarík J: Interferon inducibility of STAT 1 activation and its prognostic significance in melanoma patients. Folia Biol 49: 142-146, 2003.

38. Sims NA, Jenkins BJ, Quinn JM, et al: Glycoprotein 130 regulates bone turnover and bone size by distinct downstream signaling pathways. J Clin Invest 113: 379-389, 2004.

39. Holmen SL, Zylstra CR, Mukherjee A, et al: Essential role of beta-catenin in postnatal bone acquisition, J Biol Chem 280 : 21162-21168, 2005.
40. Gaur T, Lengner CJ, Hovhannisyan H, et al: Canonical WNT signaling promotes osteogenesis by directly stimulating Runx2 gene expression. J Biol Chem 280: 33132-33140, 2005.

41. Goldring SR and Goldring MB: Eating bone or adding it: the Wnt pathway decides. Nat Med 13: 133-134, 2007.

42. Matsubayashi S, Nakashima M, Kumagai K, et al: Immunohistochemical analyses of beta-catenin and cyclin D1 expression in giant cell tumor of bone (GCTB): a possible role of Wnt pathway in GCTB tumorigenesis. Pathol Res Pract 205: 626-633, 2009.

43. Gamberi G, Benassi MS, Böhling T, et al: Prognostic relevance of C-myc gene expression in giant-cell tmnor of bone. J Orthop Res 16: 1-7, 1998

44. Ridley AJ: Rho GTPases and actin dynamics in membrane protrusions and vesicle trafficking. Trends Cell Biol 16: 522-529, 2006.

45. Stallings-Mann ML, Waldmann J, Zhang Y, Miller E and Gauthier ML: Matrix metalloproteinase induction of Rac1b, a key effector of lung cancer progression. Sci Transl Med 4: 142ra95, 2012.

46. McAllister SS: Got a light? Illuminating lung cancer. Sci Transl Med $4: 142 \mathrm{fs} 22,2012$.

47. Wang L, Kuang L, Pan X, et al: Isoalvaxant hone inhibits colon cancer cell proliferation, migration and invasion through inactivating Racl and AP-1. Int J Cancer 127: 1220-1229, 2010.

48. Fukuda A, Hikita A, Wakeyama H, et al: Regulation of osteoclast apoptosis and motility by small GTPase binding protein Rac1. J Bone Miner Res 20: 2245-2253, 2005. 